\title{
The role of virtual reality in improving motor performance as revealed by EEG: a randomized clinical trial
}

\author{
Rocco Salvatore Calabrò ${ }^{*}$, Antonino Naro ${ }^{\dagger}$, Margherita Russo, Antonino Leo, Rosaria De Luca, Tina Balletta, \\ Antonio Buda, Gianluca La Rosa, Alessia Bramanti and Placido Bramanti
}

\begin{abstract}
Background: Many studies have demonstrated the usefulness of repetitive task practice by using robotic-assisted gait training (RAGT) devices, including Lokomat, for the treatment of lower limb paresis. Virtual reality (VR) has proved to be a valuable tool to improve neurorehabilitation training. The aim of our pilot randomized clinical trial was to understand the neurophysiological basis of motor function recovery induced by the association between RAGT (by using Lokomat device) and VR (an animated avatar in a 2D VR) by studying electroencephalographic (EEG) oscillations.
\end{abstract}

Methods: Twenty-four patients suffering from a first unilateral ischemic stroke in the chronic phase were randomized into two groups. One group performed 40 sessions of Lokomat with VR (RAGT + VR), whereas the other group underwent Lokomat without VR (RAGT-VR). The outcomes (clinical, kinematic, and EEG) were measured before and after the robotic intervention.

Results: As compared to the RAGT-VR group, all the patients of the RAGT + VR group improved in the Rivermead Mobility Index and Tinetti Performance Oriented Mobility Assessment. Moreover, they showed stronger event-related spectral perturbations in the high- $\gamma$ and $\beta$ bands and larger fronto-central cortical activations in the affected hemisphere.

Conclusions: The robotic-based rehabilitation combined with VR in patients with chronic hemiparesis induced an improvement in gait and balance. EEG data suggest that the use of VR may entrain several brain areas (probably encompassing the mirror neuron system) involved in motor planning and learning, thus leading to an enhanced motor performance.

Trial registration: Retrospectively registered in Clinical Trials on 21-11-2016, n.NCT02971371.

Keywords: Lokomat, Ersp, Loreta, Mirror neuron system, Virtual reality

\section{Background}

Virtual reality (VR) is the simulation of a real environment generated by a computer software and experienced by the user through a human-machine interface [1]. This interface enables the patient to perceive the environment as real and 3D (i.e., the sense of presence), thus increasing patient's engagement (i.e., embodiment) [2]. Hence, VR can be used to provide the patient with repetitive, task-specific training (as opposed to simply using a limb by chance) that are effective

\footnotetext{
* Correspondence: salbro77@tiscali.it

${ }^{\dagger}$ Equal contributors

IRCCS Centro Neurolesi "Bonino-Pulejo", Messina, Italy
}

for motor learning functions [3-6]. In fact, VR provides the patient with multisensory feedbacks that can potentiate the use-dependent plasticity processes within the sensorymotor cortex, thus promoting/enhancing functional motor recovery [7-14]. Furthermore, VR can increase patients' motivation during rehabilitation by decreasing the perception of exertion [8], thus allowing patients to exercise more effortlessly and regularly [9].

It is possible to magnify the sense of presence by manipulating the characteristics of the VR, including screen size, duration of exposure, the realism of the presentation, and the use of animated avatar, i.e., a third-person 
view of the user that appears as a player in the VR [15]. About that, the use of an avatar may strengthen the usedependent plastic changes within higher sensorymotor areas belonging to the mirror neuron system (MNS) [16-18]. In fact, the observation of an action, even simulated (on a screen, as in the case of VR), allows the recruitment of stored motor programs that would promote, in turn, movement execution recovery $[19,20]$. These processes are expressed by wide changes in $\alpha$ and $\beta$ oscillation magnitude at the electroencephalography (EEG) (including an $\alpha$ activity decrease and a $\beta$ activity increase) across the brain areas putatively belonging to the MNS (including the inferior frontal gyrus, the lower part of the precentral gyrus, the rostral part of the inferior parietal lobule, and the temporal, occipital and parietal visual areas) $[8,9,21,22]$.

In the last years, motor function recovery has benefited from the use of robotic devices. In particular, robot-assisted gait training (RAGT) provides the patient with highly repeated movement execution, whose feedback, in turn, permits to boost the abovementioned use-dependent plasticity processes [23]. RAGT has been combined with VR to further improve gait in patients suffering from different neurologic diseases [24]. Nonetheless, the knowledge of the neurophysiologic substrate underpinning neurorobotic and VR interaction is still poor [25, 26]. Indeed, a better understanding of this interaction would allow physician to design more personalized rehabilitative approaches concerning the individual brain plasticity potential to be harnessed to gain functional recovery [27].

The relative suppression of the $\mu$ rhythm is considered as the main index of MNS activity [28]. Nonetheless, conjugating VR and neurorobotic could make brain dynamics more complex, because of many factors related to motor control and psychological aspects come into play, including intrinsic motivation, selective attention, goal setting, working memory, decision making, positive self-concept, and self-control. Altogether, these aspects may modify and extend the range of brain rhythms deriving from different cortical areas related to MNS activation by locomotion, including theta and gamma oscillations [29-31]. Specifically, theta activity has been related to the retrieval of stored motor memory traces, whereas the gamma may be linked to the conscious access to visual target representations [30, 31]. Such broadband involvement may be due to the recruitment of multiple brain pathways expressing both bottom-up (automatic recruitment of movement simulation) and top-down (taskdriven) neural processes within the MNS implicated in locomotion recognition [32]. A recent work has shown that observed, executed, and imagined action representations are decoded from putative mirror neuron areas, including Broca's area and ventral premotor cortex, which have a complex interplay with the traditional MNS areas generating the $\mu$ rhythm [33].

Therefore, we hypothesized that the combined use of VR and RAGT may induce a stronger and wider modification of the brain oscillations deriving from the putative MNS areas, thus augmenting locomotor function gain $[34,35]$. The aim of our pilot randomized clinical trial was to understand the neurophysiological basis underpinning gait recovery induced by the observation of an animated avatar in a 2D VR while performing RAGT by studying the temporal patterns of broadband cortical activations.

\section{Methods}

\section{Participants}

The present randomized clinical trial was conducted according to the CONSORT guidelines [36]. The trial was designed as a pilot, prospective, assessor blinded, parallel group study, and was performed at the IRCCS Centro Neurolesi "Bonino-Pulejo" (Messina, Italy). Eligible patients were enrolled between October 2015 and February 2016, according to the following criteria: (i) age $\geq 55$ years; (ii) a first-ever ischemic supra-tentorial stroke (confirmed by magnetic resonance imaging -MRI) at least 6 months before their enrollment; (iii) an unilateral hemiparesis, with a Muscle Research Council -MRC- score $\leq 3$ (a score of 3 indicates that muscle strength is reduced so that the joint can be moved only against gravity with the examiner's resistance completely removed; $2=$ muscle can move only if the resistance of gravity is removed; $1=$ only a trace of movement; $0=$ no movement observed) [37]; (iv) ability to follow verbal instructions, with a Mini-Mental State Examination $>24$; (v) a mild to moderate spasticity of muscles of hip, knee, and ankle (according to a Modified Ashworth Scale, MAS, s2) [38]; (vi) ability to perform manual gait training with or without external devices (Functional Ambulatory Categories 0-4). (vii) no severe bone or joint disease; and (viii) no history of concomitant neurodegenerative diseases or brain surgery.

We preferred to select patients with a first-ever ischemic supra-tentorial stroke, as this represents a better model of stroke lesion to perform EEG analysis. In fact, multiple vascular lesions could represent a significant limit for data interpretation, as they can generate variable signals that can interfere with signal recording. For instance, it has been reported that hemispheric powers differ clearly in single acute ischemic episodes, but correlate less well with the subtle, multifocal, or more gradual changes [39]. Moreover, single lesion model is more suitable to study interhemispheric balance. Last, patients with multiple vascular lesions may have different functional recovery. For the same reason, we limited the age of inclusion to $>55$, because beneath this age it is necessary to take into account other several, additional risk factors (including 
hemostatic, inflammatory and autoimmune factors, and cardioembolic sources, such as patent foramen ovale) that altogether increase the risk of multiple vascular lesions and may account for heterogeneity of sample [40].

Clinic-demographic characteristics are reported in Table 1. All participants gave informed consent before study participation. Additionally, written informed consent for publication of clinical images was obtained from the participants. Approval was obtained from our local Ethics Committee before beginning the study (study number registration 43/ 2013). The study was retrospectively registered in Clinical Trials on 21-11-2016, n.NCT02971371.

\section{Sample size}

The sample size estimate was based on extrapolations from previous studies examining the effects of VR on gait

Table 1 Shows the individual clinical-demographic characteristics. There were no significant between-group differences in any parameter

\begin{tabular}{|c|c|c|c|c|c|}
\hline group & age & gender & $\begin{array}{l}\text { lesion } \\
\text { location }\end{array}$ & stroke onset & comorbidities \\
\hline \multirow[t]{12}{*}{ RAGT + VR } & 68 & M & $r F P$ & 12 & 3 \\
\hline & 63 & M & I PO & 7 & 2,3 \\
\hline & 57 & M & r TP & 5 & 1,4 \\
\hline & 62 & $\mathrm{~F}$ & $\mathrm{I} P O$ & 7 & 1 \\
\hline & 60 & M & rFP & 6 & 1,2 \\
\hline & 59 & M & rP & 10 & 2,3 \\
\hline & 66 & M & I F & 6 & 3 \\
\hline & 56 & $\mathrm{~F}$ & rFP & 10 & 1,2 \\
\hline & 58 & M & I PO & 8 & $1,2,4$ \\
\hline & 55 & $\mathrm{~F}$ & rFP & 8 & 1,4 \\
\hline & 65 & $\mathrm{~F}$ & I PO & 8 & 1,3 \\
\hline & 55 & $\mathrm{~F}$ & r TP & 7 & 1,4 \\
\hline mean $\pm S D$ & $60 \pm 4$ & $7 \mathrm{M} ; 5 \mathrm{~F}$ & & $8 \pm 2$ & \\
\hline \multirow[t]{12}{*}{ RAGT-VR } & 58 & M & rP & 8 & $1,3,5$ \\
\hline & 72 & $\mathrm{~F}$ & IF & 11 & 2,3 \\
\hline & 59 & M & IF & 5 & 1,2 \\
\hline & 54 & M & $r P$ & 5 & 2 \\
\hline & 55 & $\mathrm{~F}$ & $r P$ & 10 & 1 \\
\hline & 73 & M & r TP & 8 & 3,5 \\
\hline & 63 & $\mathrm{~F}$ & I TP & 8 & 2,2 \\
\hline & 64 & M & $r P$ & 11 & 2,3 \\
\hline & 64 & $\mathrm{~F}$ & I F & 6 & 3 \\
\hline & 65 & M & $r P$ & 8 & $1,3,5$ \\
\hline & 65 & $\mathrm{~F}$ & IF & 8 & 2,3 \\
\hline & 66 & M & I F & 8 & 3 \\
\hline mean $\pm S D$ & $63 \pm 6$ & $7 \mathrm{M} ; 5 \mathrm{~F}$ & & $8 \pm 2$ & \\
\hline
\end{tabular}

Legend: $F$ frontal; $P$ parietal; $O$ occipital; $T$ temporal; / left; $r$ right; 1 high blood pressure; 2 diabetes mellitus; 3 hypercholesterolemia; 4 smoking; 5 alcoholism in patients with stroke [41-44]. Accordingly, we used the effect size (0.9) of the primary composite endpoint for calculations. Power was set at $80 \%$, alpha at $5 \%$; we accounted for a dropout rate of $10 \%$. Using a relatively conservative estimation, a total of 50 subjects ( 25 in each group) would be required to detect a difference of at least $20 \%$ in the primary outcome between the two treatment groups assuming non-inferiority with moderate correlations among covariates $(\mathrm{R}$-squared $=0.5)$.

\section{Study design}

Thirty-five patients were assessed for eligibility according to the inclusion/exclusion criteria. Then, 24 patients were equally randomized into the RAGT + VR or RAGT-VR group with a 1:1 allocation ratio. For randomization, sealed envelopes were prepared in advance and marked on the inside with $\mathrm{a}+\mathrm{VR}$ or $-\mathrm{VR}$. The intervention period of both groups was identical, five sessions per week for eight consecutive weeks, 45min for each session. We registered the EEG in the morning of the second day of the first week $\left(\mathrm{T}_{\mathrm{PRE}}\right)$ and the last day of the last week of treatment $\left(\mathrm{T}_{\mathrm{POST}}\right)$. Clinic and kinematic assessment was performed immediately before and after the Lokomat training. In addition, a physiotherapist supervised patients' cooperation and participation to Lokomat training. The experimenters who analyzed the data and the therapists who performed the clinical tests were blind on patient allocation. Moreover, patients were not informed on the content of the VR adopted in the two groups.

\section{RAGT intervention}

Prior to the Lokomat training, all participants became familiarized with the Lokomat-Pro (RAGT + VR) or Lokomat-Nanos (RAGT-VR) (Hocoma AG; Volketswil, Switzerland), and had individually adapted their body weight support (BWS), leg guidance force (GF), and foot-lifting straps (that assisted ankle dorsiflexion for adequate toe clearance during the swing phase). Gait speed was set at a maximum of $1.8 \mathrm{~m} / \mathrm{s}$. Patients were asked to walk with their maximal effort. Then, patients were randomly assigned to RAGT + VR or RAGT-VR group. Both groups performed 40 Lokomat sessions (each lasting 40-45 $\mathrm{min}$ ), five times a week, between $9^{\mathrm{am}}$ and $11^{\mathrm{am}}$. The RAGT + VR group received a visual feedback showing a VR run game where the patient had to collect or avoid objects, to motivate him/her to walk actively (Fig. 1). Each avatar's leg movement corresponded to that performed by the patient. To this end, we employed an impedance-based control strategy [45, 46], which allows variable deviations from a given leg trajectory, thus making the orthosis feel compliant (instead of making the orthosis stiff, i.e., allowing only negligible 


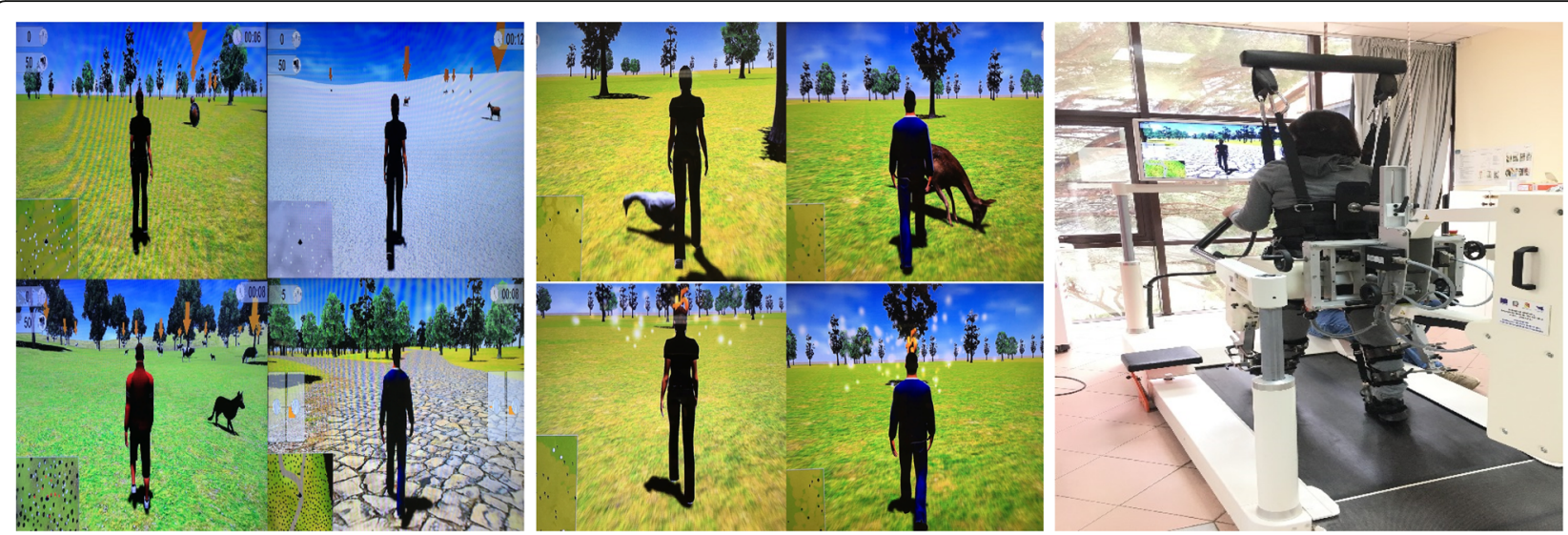

Fig. 1 The virtual mirror (left), a sequence of the visual feedback (central), and combined visual-haptic modality (right)

deviations from the set trajectory). The Lokomat is equipped with potentiometers and force transducers, capable of providing feedback about joint movement and joint moment production, respectively. In the impedance-based control strategy, the joint moment acting on the subject's leg (which is generated by the force transducers of the orthoses) is proportional to the angular deviation of the performed movement from the preprogrammed movement. Therefore, the patient perceives the stiffness of the orthosis based on the setting of the mechanical impedance value (i.e., zero impedance makes no feedback experienceable, whereas maximal impedance results in maximal stiffness, equal to the position controller). The stiffness of the orthoses was set to the lowest point where subjects reported feeling the inertia of the Lokomat segments (about $30 \%$ of the maximal Lokomat impedance).

On the other hand, the RAGT-VR group was not provided an avatar but a smile, indicating the goodness of the leg movements. The biofeedback of the Lokomat gait orthosis is based on the interaction torques between the participant and the orthosis. To this end, hip and knee linear drives are equipped with force sensors that measure the human-machine interaction forces at the hip and knee joints for stance and swing phase, which are required to keep the participant on a predefined gait trajectory. The weighting functions of the gait cycle were defined for each part so that the resulting biofeedback values increased for therapeutically desirable movements, i.e. hip and knee flexion-extension force. Thus, biofeedback force values (representing the physical activity of the participants) were positive when the patient was actively participating and negative when passively participating in Lokomat training (or when muscles were inappropriately or involuntary activated) [36]. We obtained an average biofeedback value for each joint in the hemiparetic leg.

\section{Virtual reality}

The 2D VR set-up consisted of a 42-in. flat-screen placed in front of the Lokomat and a 7.1 Dolby Surround system (Fig. 1). The Lokomat device served as a multimodal feedback system: the human-machine interaction forces measured from the Lokomat device were used as an input device for the patient's movements into the VR (i.e., to animate the motion of the human figure in VR at a $60 \mathrm{~Hz}$ refresh rate in real time on the screen - virtual mirror. There was no lag between motions of the subject and virtual figure) or the smiling face. The orthosis guided subject's leg movements in the sagittal plane within individually adapted hip and knee joint trajectories. Lokomat potentiometers provided real-time information of the subject's hip and knee angles. The measured joint angles were used to animate the subject's human figure in the virtual mirror. The distance between the subject and projection screen was $1.5 \mathrm{~m}$. Furthermore, since the run lane was not always straight, the VR running game used an asymmetrical physical activity of the legs to induce turning in the virtual environment. In particular, turning right and left was induced by increasing the activity of the contralateral leg of the desired direction and, respectively, decreasing the activity of the ipsilateral one. Lokomat device provided visual and acoustic feedback that reflected the interactions with objects represented in the virtual environment (e.g., the boundaries of the run lane, or objects to be avoided or collected). Further, Lokomat provided haptic feedback by the gait orthosis, so that the subjects using the device were provided with a haptic experience from proprioceptive (joint angles) feedback about their movements [47, 48].

The use of $2 \mathrm{D}$ displays, which are not as realistic as the true stereo $3 \mathrm{D}$ ones (full-3D VR), are akin to looking at a scene through a window and offer a limited sense of presence, potentially limiting the significance of our findings. We potentially provided a 
higher sense of presence by using depth cues, such as perspective, relative motion, occlusion, and aerial perspective, despite the use of a 2D VR [7].

\section{EEG recording and preprocessing}

EEG was recorded using a Brain-Quick System (Micromed; Mogliano Veneto, Italy), from standard 19 electrodes headset according to the International 10-20 system (Fp1, Fp2, F7, F3, Fz, F4, F8, T3, C3, Cz, C4, T4, T5, P3, Pz, P4, T6, O1, O2, ground on the forehead), for 10 min while performing Lokomat training. To monitor eye movements, an electro-oculogram (EOG) with a bipolar montage (one pair of electrodes traced horizontal eye movements, a second pair the vertical ones) was also collected. EEG end EOG were sampled at $500 \mathrm{~Hz}$, high pass filtered at $1 \mathrm{~Hz}$ using a zerophase FIR filter (order $7500)$ to minimize drifts, low pass filtered at $200 \mathrm{~Hz}$ (zerophase FIR filter order 36), and referenced to $\mathrm{Cz}$ [49]. An adaptive filter was applied to allow real-time filtering of signals recorded from EOG [50, 51].

Electrode impedance was kept below $5 \mathrm{k} \Omega$. During the entire EEG recording (as well as during the entire gait training), an experimenter checked for possible signs of drowsiness (e.g., abrupt worsening in gait performance, closed eyes, increase of proportion of theta and alpha activity in the eyes-open condition) [52], which were counted (given that monotonous gait pattern provided by RAGT may tend to induce sleepiness, thus decreasing arousal that negatively affects gait training progress). Patients were prohibited from drinking coffee, smoking, and change their bedtime during the three days prior EEG recording.

Infomax independent component analysis (ICA) was computed on the preprocessed EEG signal to decompose neural and artefactual sources [53-57]. In detail, ICA was computed two times. First, $500 \mathrm{~ms}$-segmented EEG signals were removed if its probability distribution exceeded the average distribution by $5 \pm \mathrm{SD}$. Then, ICA was computed to reject epochs based on the probability distribution of the IC projections. Thus, EEG segments were re-filtered $(8-40 \mathrm{~Hz})$ and a second ICA was computed a second time. The so-obtained IC were grouped into clusters using a k-means algorithm (based on the feature vector of dipole location, power spectra, and scalp map). The IC closest to the cluster centroid was remained for each subject, so to have equal contribution of each subject to the cluster-wise analysis.

\section{EEG analysis}

EEG analysis consisted of the computation of the power spectral density (PSD) (using Welch's Method) and the time-frequency analysis to evaluate Event-related-spectralperturbations (ERSPs) for each IC [58].
EEG was segmented into $1.4 \mathrm{~s}$ epochs $(-700 ; 700) \mathrm{ms}$ with regard to the heel strike (HS) (i.e., the first moment the foot comes into contact with the floor) [59], thus obtaining 428 epochs. About that, the force-sensing resistor of the Lokomat device detected the movement onset of both lower limbs, which was synchronized with the EEG data. Epochs were rejected by using an automatic artifact rejection method (epochs with values of $[-100 ; 100] \mu \mathrm{V}, \geq 5 \mathrm{SD}$ of the mean kurtosis value, $\geq 5 \mathrm{SD}$ of the mean probability distribution, drifts of $\geq 50 \mu \mathrm{V} /$ epoch and with a $R^{2}$ limit $\leq 0.3$, spectra deviating from the mean by $\pm 50 \mathrm{~dB}$ in the $0-2 \mathrm{~Hz}$ frequency window and by $[-100 ; 50] \mathrm{dB}$ in the $20-100 \mathrm{~Hz}$ frequency window), visually inspection for artifacts, and if the power perturbation in the $20-40 \mathrm{~Hz}$ band deviated by +25 or $-100 \mathrm{~dB}$ from the baseline at least for one IC $[57,60]$. Rejection rate was $5 \%$. This low rate is not surprising, given that it has been shown that scalp EEG recording during low-speed treadmill walking is not invalidated by excessive artefacts [61]. After this, the segmented data were time-warped and averaged together for all strides, so that initial affected-side heel strike, unaffected-side toe off, unaffected-side heel strike, affected-side toe off, and the subsequent affectedside heel strike occurred at the same times [49]. Spectrum analysis was carried using a standard fast Fourier transform (FFT) algorithm (Hanning-window, frequency resolution $0.7 \mathrm{~Hz})$ within $9(4-7 \mathrm{~Hz}), \mu(8-12 \mathrm{~Hz}), \beta(12-$ $30 \mathrm{~Hz})$, low- $\gamma(\mathrm{L} \gamma)(31-45 \mathrm{~Hz})$, and high- $\gamma(\mathrm{H} \gamma)(46-70 \mathrm{~Hz})$ bands $[62,63]$, and related to the phases of the gait cycle [55]. We opted to analyze these rhythms as it has been reported a different, specific role of each oscillation in sensory-motor pattern [27-35, 64]. For instance, there is evidence for a difference between the low and high $\alpha$ oscillations, which express action execution and observation, respectively $[65,66]$.

Single trial spectograms were computed and timewarped (thus aligning the time-points for right and left heel strike) over trials using a linear interpolation function to generate gait cycle ERSPs (i.e., epochs were based on the heel strike events, being the unaffected-side, the affectedside, and the next unaffected-side heel strike time-warped to $0,50 \%$, and $100 \%$ of the gait cycle, respectively). Relative changes in spectral power were obtained by averaging the difference between each single-trial log spectogram and baseline (the mean IC log spectrum over all gait cycles per training) [49]. To visualize significant ERSP changes, deviations from the average gait cycle log spectrum were computed with a bootstrap method [56, 57]. For statistical concern, bandwidth ERSP of each IC were averaged within each $10 \%$ of the gait cycle (10-point ERPS curve, frequency resolution $0.7 \mathrm{~Hz}$ ) [67]. The average log spectrum for all movement cycles was subtracted from the log spectrogram for each movement cycle. We thus calculated the resulting PSD changes from this baseline (defined as the percentage 
decrement, event-related desynchronization -ERD- and increment, event-related synchronization -ERS- as a function of the percentage of the normalized gait cycle) [53] for each band and electrode-group of interest (with regard to the areas of activation of MNS reported in the literature [68], i.e., ipsi and contralesional frontal -Fp1/F7/F3, Fp2/F8/F4-, central -T3/C3, T4/C4- and parieto-occipital -T5/P3/O1, T6/P4/O2) [69-73].

\section{Source localization}

The source localization approach allows examining brain activities in various sources at different temporal phases of motor control. Because of high temporal resolution of the EEG signals, brain activities before and after the movement onset can be localized in order to distinguish cortical activities related to both motor planning (movement preparation) and motor execution (corticospinal pathway activation). The Estimation of Current Densities was carried by using Low Resolution Brain Electromagnetic Tomography (LORETA; free release of LORETA-KEY alphasoftware) [63, 74-76]. The main components detected with the ICA (signal-to-noise ratio > 1) were chosen for the source reconstruction. The distributed current density model (LORETA) with L1 norm method (based on the Montréal Neurological Institute (MNI) brain MRI) was then applied to the ICA data [77, 78]. The sources were constrained to the reconstructed layer of the folded cortex $[79,80]$.

\section{Outcome measures}

The primary endpoint, with respect to VR efficacy in post-stroke condition, was the proportion of patients achieving a $20 \%$ improvement in lower limb gait and balance at the end of the training, as measured by the Rivermead Mobility Index (RMI), the Tinetti Performance Oriented Mobility Assessment (POMA), and the gait cycle-related ERSPs. Indeed, a 20\% improvement correspond to a significant minimal detectable change in RMI [81] and POMA [82]. According to previous work on assisted gait training in post-stroke patients, these changes are paralleled by EEG signal modification of at least $20 \%$ to be significant $[83,84]$.

As secondary outcomes, we considered the global MAS score derived from the muscles of hip, knee, and ankle, the Hamilton Rating Scale for Depression (HRS), the hip and knee flexion/extension force measured by the RAGT device, the extent to which a patient felt him/ herself entrained in the VR training (reported on a visual analogue scale -VAS- ranging from zero -not at all- to ten -very much), and the mean of the episodes of drowsiness.

\section{Statistical analysis}

The normal distribution of the data was evaluated with the Kolmogorov-Smirnov test. Baseline data were compared between the two groups using a Student $t$ test for continuous variables if data were normally distributed, whereas a Mann-Whitney U test was used for non-normally distributed ordinal scale. Likewise, Wilcoxon test, Mann-Whitney $U$ test, or t-test were used for within-group and between-group comparisons, depending on the types of data measurements.

The ERD/ERS changes for each frequency band were assessed by means of three-way ANOVA for repeated measures, employing the factor time (two levels: $\mathrm{T}_{\mathrm{PRE}}$ and $\mathrm{T}_{\mathrm{POST}}$ ) and electrode-set (three levels: frontal, central, and parieto-occipital) as withinsubject factors, and group (two levels: RAGT + VR and RAGT-VR) as between-subject factor. Based on the significance of the F-value, post-hoc paired-sample $t$-tests were carried out to assess the significance of interactions (Bonferroni correction). A $p$-value $<0.05$ was considered significant.

BWS and GF were included as covariates in the ANOVA analysis. In fact, it has been reported that RAGT training usually implies a steady progression of BWS and GF across the training program, so it is necessary to update and analyze these parameters in relation to the assessment of the outcomes [85]. In fact, both BWS and GF can influence spatiotemporal movement characteristics, thus affecting functional gait pattern. Indeed, finely tuning BWS and GF may somehow improve possible spatiotemporal gait asymmetries. On the other hand, missing the correction of these parameters augments inter-limb gait asymmetry for an extended duration in people with stroke [86]. Besides the factor electrode-set (which was employed in the ANOVA analysis to carry the spatio-temporal analysis of EEG signals at scalp level), we also added the factors lesion localization as covariate in the ANOVA analysis (according to the localization within left or right frontal, parietal, occipital, and temporal lobe). Such factor was added to augment inter-subject evaluation, as the sample was non-homogeneous for stroke localization, which can affect EEG signals beyond the overhead electrodes [87], also influencing both motor deficit degree and recovery [88].

ERSPs were computed in each frequency range for RAGT + VR and RAGT-VR using the average gait cycle log spectrum computed from the RAGT-VR as common baseline. The gait cycle was divided into in two stationary (S1, 10-30\%, and S2, 60-80\%) and two transition phases (T1, 30-60\%, and T2, 80-10\%). The stationary phases correspond to the midstance (10-30\%), initial swing (60-70\%), and midswing phases (70-90\%), whereas the transition phases correspond to the terminal stance (30-50\%), 
preswing (50-60\%), terminal swing (90-100\%), and loading response (0-10\%) [89]. An ANOVA for repeated measures with the factors time (in relation with the gait cycle phases) (eight levels: two PRE and POST stationary and two PRE and POST transition phases), electrode-set (three levels: frontal, central, and parieto-occipital), and group (two levels: RAGT + VR and RAGT-VR) was computed for each frequency band. Multiple comparisons were corrected controlling for false discovery rate $(p<0.05)$ [90]. Sphericity assumption violations were Greenhouse-Geisser corrected.

\section{Results}

\section{Participant flow}

We summarized in the CONSORT flow diagram (Fig. 2): the numbers of participants who were randomly assigned, who received the intended treatment, and who were analyzed for the primary outcome; the losses and exclusions during periods of recruitment, randomization, and follow-up. All treated patients completed the robotic training without reporting any side effect (Fig. 2). The main analysis focused on the consequences of the avatar observation on the RMI, POMA, and gait-related ERS/ ERD, and involved all the patients who were randomly assigned to the two groups. Twelve patients were enrolled in each group (RAGT + VR: mean age $60 \pm 4$ years, 7 males and 5 females, disease duration $8 \pm 2$ months;
RAGT-VR: mean age, $63 \pm 6$ years, 7 males and 5 females, disease duration $8 \pm 2$ months) (Table 1). There were no significant differences concerning any parameter between the two groups. Mean and standard deviation values of all outcome measures are reported in Table 1.

\section{Clinical and kinematic data}

RMI improved more in the RAGT + VR than the RAGT-VR group, whereas POMA improved only in the RAGT + VR group (Table 2). HRS score equally decreased in both groups. MAS did not change significantly in both groups. VAS improved only in RAGT + VR group (Table 2). Knee force showed a greater improvement in RAGT + VR than RAGT-VR group, whereas hip force improved only in RAGT + VR group (Table 2).

\section{Electrophysiological data}

We found three main areas of brain activation that were more evident in the RAGT + VR group as compared to the RAGT-VR group across the gait cycle (Fig. 3a): (1) BA6 (Tailarach coordinates -x,y,z- 5, -1, 60); (2) BA7 $(-14,-56,53)$; and (3) BA17 $(-20,-88,3)$.

Concerning frontal activation (Fig. 3b; Table 3), RAGT + VR induced significant $\mu / \beta$ ERSP changes from

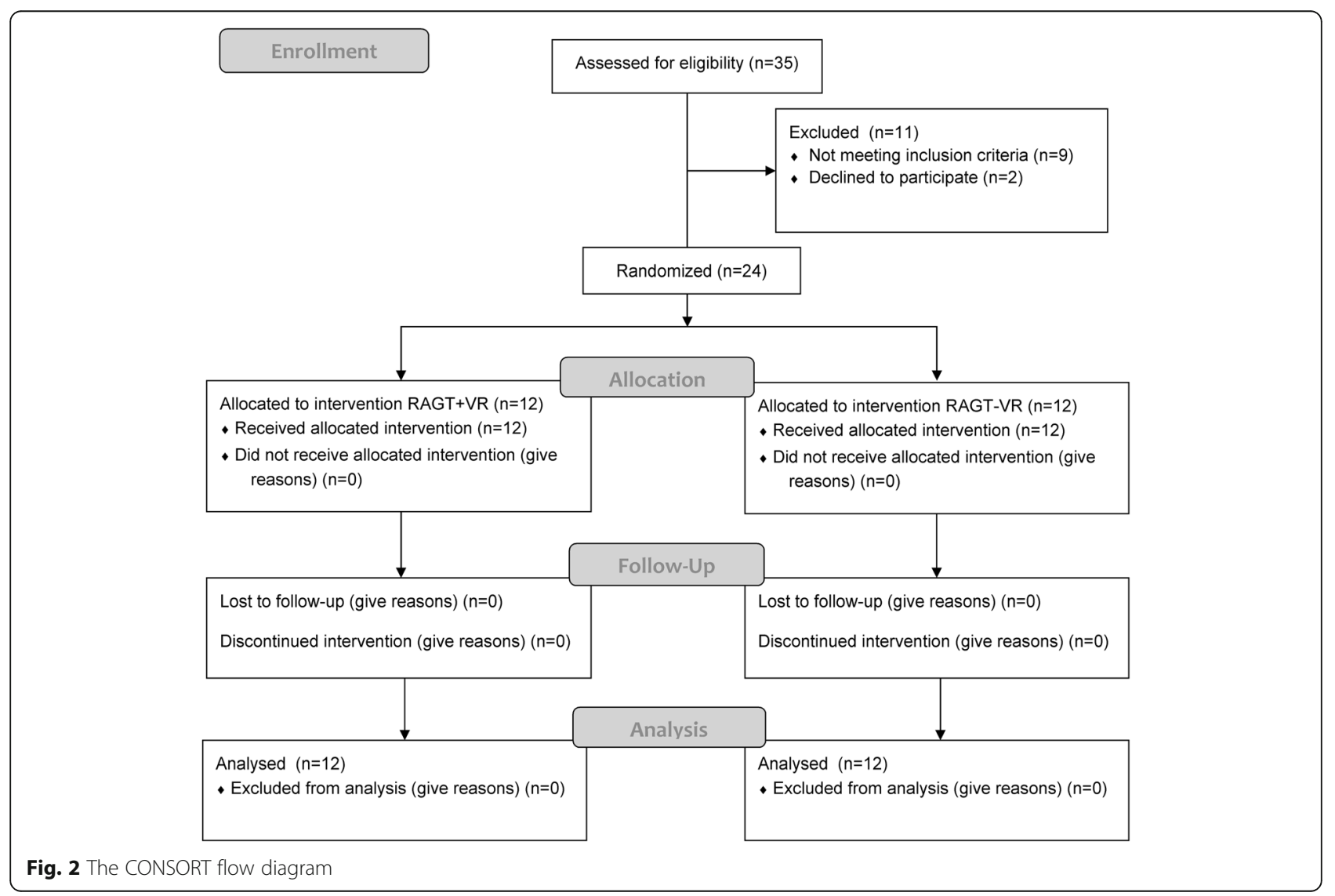


Table 2 Mean values $( \pm \mathrm{SD}$ ) of clinical outcomes measure after RAGT \pm VR. Within- and between-group comparisons, with confidence interval (95\%) (Cl), are reported. Not reported data are non-significant

\begin{tabular}{|c|c|c|c|c|c|c|}
\hline PARAMETER & GROUP & PRE & POST & WITHIN-GROUP & BETWEEN-GROUP & $\mathrm{Cl}(95 \%)$ \\
\hline \multirow[t]{2}{*}{ RMI } & RAGT + VR & $8 \pm 1$ & $14 \pm 1$ & $<0.001$ & 0.001 & 1.2 то 7.6 \\
\hline & RAGT-VR & $7 \pm 1$ & $9 \pm 1$ & 0.01 & & \\
\hline \multirow[t]{2}{*}{ POMA } & RAGT + VR & $17 \pm 3$ & $23 \pm 3$ & 0.001 & 0.01 & 1.2 то 7.6 \\
\hline & RAGT-VR & $12 \pm 4$ & $15 \pm 4$ & & & \\
\hline \multirow[t]{2}{*}{ MAS } & RAGT + VR & $2 \pm 0.5$ & $2 \pm 0.5$ & & & \\
\hline & RAGT-VR & $2 \pm 0.5$ & $2 \pm 0.5$ & & & \\
\hline \multirow[t]{2}{*}{ HRS } & $R A G T+V R$ & $11 \pm 3$ & $7 \pm 3$ & 0.01 & & \\
\hline & RAGT-VR & $13 \pm 3$ & $10 \pm 3$ & 0.02 & & \\
\hline \multirow[t]{2}{*}{ VAS } & RAGT + VR & $6 \pm 1$ & $8 \pm 1$ & $<0.001$ & 0.01 & 1.3 то 15.3 \\
\hline & RAGT-VR & $5 \pm 1$ & $6 \pm 1$ & & & \\
\hline \multirow[t]{2}{*}{ DROWSINESS EPISODES } & $R A G T+V R$ & $5 \pm 1$ & $2 \pm 1$ & $<0.001$ & 0.009 & 1 то 6.9 \\
\hline & RAGT-VR & $5 \pm 1$ & $5 \pm 1$ & & & \\
\hline \multirow[t]{2}{*}{ HIP FORCE } & $R A G T+V R$ & $36 \pm 7$ & $42 \pm 3$ & 0.01 & 0.02 & -6.2 то -3.8 \\
\hline & RAGT-VR & $34 \pm 6$ & $38 \pm 10$ & & & \\
\hline \multirow[t]{2}{*}{ KNEE FORCE } & $R A G T+V R$ & $31 \pm 8$ & $47 \pm 6$ & $<0.001$ & 0.02 & \\
\hline & RAGT-VR & $30 \pm 7$ & $36 \pm 3$ & 0.04 & & \\
\hline
\end{tabular}

Legend: RMI Rivermead Mobility Index; POMA Tinetti Performance Oriented Mobility Assessment; MAS Modified Ashwort Scale; HRS Hamilton Rating Scale for depression; VAS visual analogic scale

baseline to S1, T1, and S2 phase of the gait cycle, as reflected by the significant interaction between gait phases and training for gait cycle related modulations concerning RAGT + VR group (Table 4). In particular, we observed a frontal ERD before the heel strike, followed by a frontal ERS during the heel strike (Fig. 4; Table 4). This changes also presented a significant difference in scalp projections between the trainings (Table 5; Fig. 5), with a greater magnitude in RAGT + VR group.

$\mu / \beta$ changes were paralleled by a significant $L \gamma$-ERS around the heel strike in both the groups and an $\mathrm{H} \gamma$ ERD from S1 to S2 (i.e., ending soon after the heel strike) only in RAGT + VR. Detailed statistical data of the main interactions and effects, and the temporal ERSP changes across the gait cycle are summarized in Tables 4 and 5 and Figs. 4 and 5 .

Concerning central areas activation (Fig. 3b; Table 3 ), we found a significant $\mu / \beta$ ERD/ERS at S1, T1, and $\mathrm{S} 2$, a brief 9 -ERS in the S1 phase, as revealed by the ANOVA and the post-hoc tests (Tables 4 and 5; Figs. 4 and 5) showing that spectral power in $\mu / \beta$ band was significantly reduced in T1 and increased in $\mathrm{S} 1$, and this was more evident in RAGT + VR than RAGT-VR.

Finally, parieto-occipital activation (Fig. 3b; Table 3) was characterized by a significant difference for $\mu$ and $\mathrm{Hy}$ (ERD) between the groups during the entire gait cycle (Tables 4 and 5; Figs. 4 and 5). Post-hoc tests showed that scalp projections were significantly strengthened in RAGT + VR as compared to RAGT-VR.

\section{Clinical-electrophysiological correlations}

We observed a significant correlation between RMI and POMA score improvement and central $\beta$-ERS $(r=0.895$, $p=0.001$ and $r=0.570, p=0.04$, respectively) and frontal Hy-ERD magnitude $(r=-0.831, p=0.003$ and $r=-0.615$, $p=0.04$, respectively). Moreover, the improvement in hip force was significantly correlated with frontal $\mathrm{H} \gamma$-ERD magnitude $(r=-0.802, p=0.004)$. Clinical-demographic characteristics (age, gender, disease duration, comorbidity) did not influence the primary outcomes.

\section{Discussion}

The main finding of our pilot study consists in the more evident activation of premotor, precuneus, and associative visual areas in the RAGT + VR group as compared to RAGT-VR group.

All the patients belonging to RAGT + VR showed a significant decrease of central $\mu / \beta$ power during the phase preceding the heel strike, followed by a power increase (as shown by the gait cycle phase dependent ERSP modulation), thus indicating higher neuronal activation [91]. Importantly, we observed that the stronger the $\mu / \beta$ ERSPs were, the higher the clinical amelioration. Given that these ERSPs are a marker of activation and deactivation/inhibition of sensorimotor areas concerning motor planning, postural stabilization, and the prediction of potential actions [92-102], our findings suggest the importance of enhancing $\mu / \beta$ ERSPs to foster locomotor training. In addition, to monitor these brain 


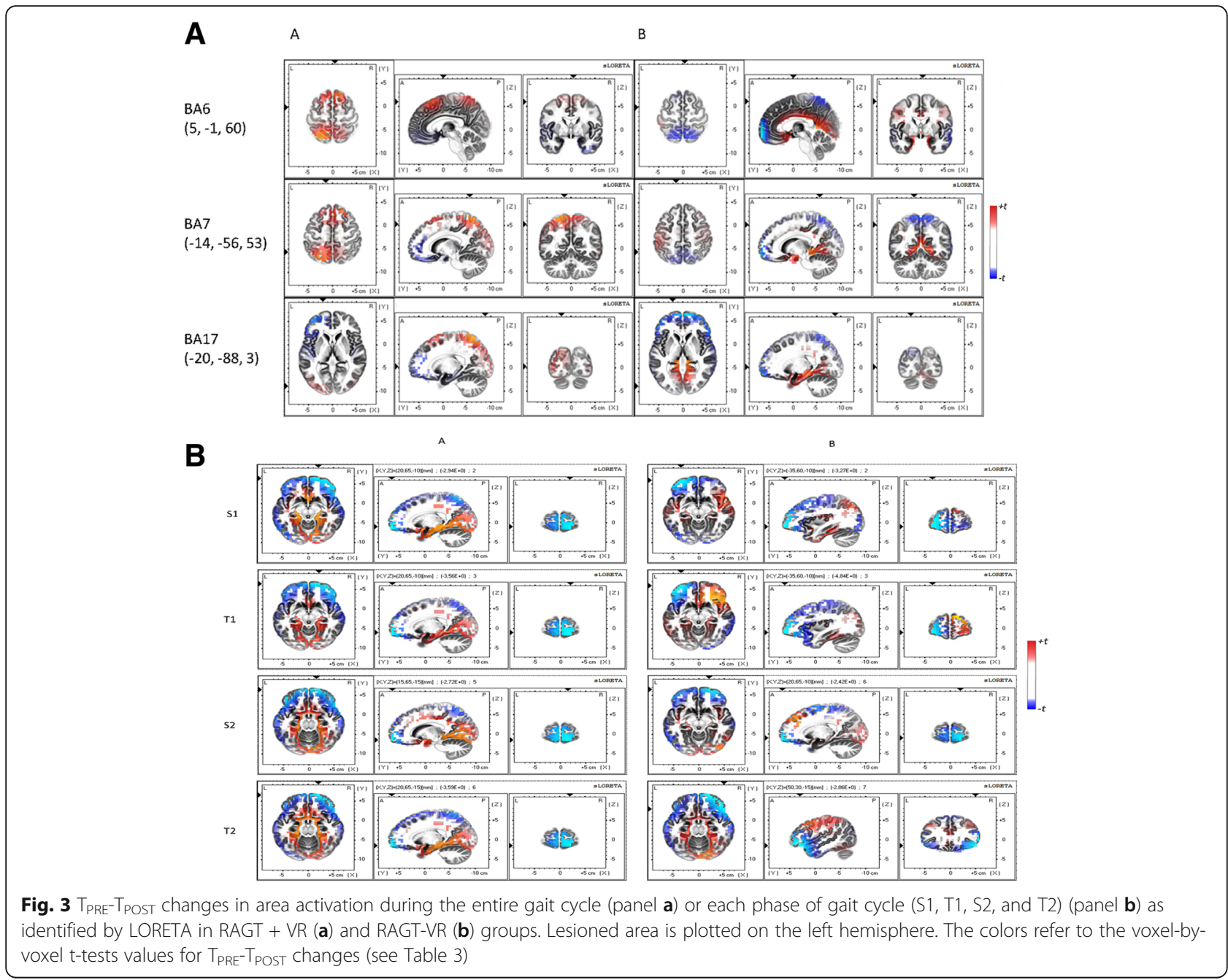

activations would allow a better patient-tailored walking training.

The novelty of our study is the significant frontoparietooccipital $\mathrm{H} \gamma$-ERD and parietooccipital $\alpha$-ERD only in the RAGT + VR group. The premotor-parietooccipital desynchronization of $\gamma$-oscillations is thought to be a marker of activation of sensorimotor and visuo-spatial associative areas concerning motor planning and selective muscle activation [91, 100, 102-112] even during active and passive RAGT [67].
We also found that the magnitude of $\gamma$-band modulation was significantly correlated with the clinical amelioration and the improvement in muscle strength, and it was paralleled by a more selective $\mu / \beta$-band modulation concerning either the temporal patterns of activation across the gait cycle or the hemispheric distribution of ERSPs. We may argue that VR may induce a functional fronto-parietooccipital $\alpha / \gamma$-band activation that, in turn, allows a more efficient motor planning and execution, as shown by a stronger and selective modulation of $\mu$

Table 3 Significant different LORETA activation (ANOVA F and $p$ values) during gait cycle at TPOST as compared to TPRE (post-hoc $p$-value). Not reported data are non-significant

\begin{tabular}{|c|c|c|c|c|c|c|c|c|c|c|c|c|}
\hline \multirow[t]{3}{*}{$t \times g \times e$} & \multicolumn{6}{|l|}{ RAGT + VR } & \multicolumn{6}{|c|}{ RAGT-VR } \\
\hline & \multirow{2}{*}{\multicolumn{2}{|c|}{$t \times e$}} & \multicolumn{4}{|c|}{$T_{\text {PRE }}-T_{\text {POST }}$ differences related to gait cycle phases } & \multirow{2}{*}{\multicolumn{2}{|c|}{$t \times e$}} & \multicolumn{4}{|c|}{$T_{\text {PRE }}{ }^{-} T_{\text {POST }}$ differences related to gait cycle phases } \\
\hline & & & S1 & $\mathrm{T} 1$ & S2 & $\mathrm{T} 2$ & & & S1 & $\mathrm{T1}$ & $\mathrm{S} 2$ & $\mathrm{~T} 2$ \\
\hline \multirow[t]{3}{*}{$21,<0.001$} & $28,<0.001$ & C & $<0.001$ & $<0.001$ & 0.03 & $<0.001$ & $8,0.01$ & C & $<0.001$ & $<0.001$ & $<0.001$ & $<0.001$ \\
\hline & & $\mathrm{F}$ & $<0.001$ & $<0.001$ & $<0.001$ & $<0.001$ & & $\mathrm{~F}$ & $<0.001$ & $<0.001$ & $<0.001$ & $<0.001$ \\
\hline & & $\mathrm{PO}$ & 0.004 & 0.005 & $<0.001$ & $<0.001$ & & $\mathrm{PO}$ & $<0.001$ & & & \\
\hline
\end{tabular}

Legend: t time, g group, e electrode, C central, F frontal, PO parieto-occipital; S1 first stationary phase; S2 second stationary phase; T1 first transition phases; T2 second transition phase 
Table 4 Summarizes the ANOVA findings concerning PRE-POST group differences of ERSP (F, p) (top) and the post-hoc p-values $(t, p)$ (bottom) related to each phase of gait cycle. Not reported data are non-significant

\begin{tabular}{|c|c|c|c|c|c|c|c|c|}
\hline \multirow[t]{2}{*}{ band } & \multirow[t]{2}{*}{$t \times g \times e$} & \multicolumn{4}{|l|}{ RAGT + VR } & \multicolumn{3}{|l|}{ RAGT-VR } \\
\hline & & $t \times e$ & $C$ & \multicolumn{2}{|l|}{$\mathrm{F}$} & $t \times e$ & $C$ & $\mathrm{~F}$ \\
\hline$\mu$ & $8.6,<0.001$ & $77,<0.001$ & $71,<0.001$ & \multicolumn{2}{|l|}{$50,<0.001$} & $16,<0.001$ & $3,0.007$ & $5,<0.001$ \\
\hline$\beta$ & $15,<0.001$ & $72,<0.001$ & $87,<0.001$ & \multicolumn{2}{|l|}{$55,<0.001$} & $39,<0.001$ & $8,<0.001$ & $9,<0.001$ \\
\hline LY & $9.2,<0.001$ & $66,<0.001$ & & \multicolumn{2}{|l|}{$53,<0.001$} & \multicolumn{2}{|l|}{$12,<0.001$} & $25,<0.001$ \\
\hline $\mathrm{HY}$ & $28,<0.001$ & $37,<0.001$ & & \multicolumn{2}{|l|}{$12,<0.001$} & & & \\
\hline$\vartheta$ & $8.9,<0.001$ & $57,<0.001$ & $51,<0.001$ & & & $10,<0.001$ & $18,<0.001$ & \\
\hline \multirow[t]{2}{*}{ band } & \multirow[t]{2}{*}{ electrode } & \multirow[t]{2}{*}{ group } & \multicolumn{3}{|c|}{ PRE-POST differences related to gait cycle phases } & & & \\
\hline & & & S1 & T1 & S2 & $\mathrm{T} 2$ & & \\
\hline \multirow[t]{6}{*}{$\mu$} & \multirow[t]{2}{*}{ C } & RAGT + VR & $3.3,0.01$ & $-14,<0.001$ & $3.4,0.01$ & & & \\
\hline & & RAGT-VR & $2.4,0.04$ & $-6.3,0.001$ & $3.3,0.01$ & & & \\
\hline & \multirow[t]{2}{*}{$\mathrm{F}$} & $R A G T+V R$ & & $5,0.002$ & $4.5,0.004$ & & & \\
\hline & & RAGT-VR & & $3.6,0.01$ & $2.7,0.03$ & & & \\
\hline & \multirow[t]{2}{*}{$\mathrm{PO}$} & RAGT + VR & $-3.4,0.01$ & $-5,0.002$ & $-3.4,0.01$ & $-3.6,0.01$ & & \\
\hline & & RAGT-VR & $-3.3,0.01$ & $4.5,0.002$ & $-3.3,0.01$ & $-2.7,0.03$ & & \\
\hline \multirow[t]{4}{*}{$\beta$} & \multirow[t]{2}{*}{ C } & $R A G T+V R$ & $-26,<0.001$ & $6,0.001$ & $4.8,0.003$ & & & \\
\hline & & RAGT-VR & $-2.9,0.02$ & $3.9,0.007$ & $2.9,0.02$ & & & \\
\hline & \multirow[t]{2}{*}{$\mathrm{F}$} & RAGT + VR & $-24,<0.001$ & $8.3,<0.001$ & $5.3,0.002$ & & & \\
\hline & & RAGT-VR & $-3.5,0.01$ & $3.5,0.02$ & $3.5,0.01$ & & & \\
\hline \multirow[t]{2}{*}{$\vartheta$} & \multirow[t]{2}{*}{ C } & RAGT + VR & $5.1,0.002$ & & & & & \\
\hline & & RAGT-VR & $3,0.02$ & & & & & \\
\hline \multirow[t]{4}{*}{$\mathrm{HY}$} & \multirow[t]{2}{*}{$F$} & RAGT + VR & $-3.5,0.01$ & $-2.6,0.03$ & $-5.2,0.002$ & & & \\
\hline & & RAGT-VR & & & & & & \\
\hline & \multirow[t]{2}{*}{$\mathrm{PO}$} & RAGT + VR & $-2.8,0.02$ & $-4.4,0.004$ & $-7,<0.001$ & $-4.5,0.003$ & & \\
\hline & & RAGT-VR & & & & & & \\
\hline \multirow[t]{4}{*}{ LY } & \multirow[t]{2}{*}{ C } & RAGT + VR & & $6,0.001$ & $5.1,0.002$ & & & \\
\hline & & RAGT-VR & & $3.5,0.02$ & $3.8,0.008$ & & & \\
\hline & \multirow[t]{2}{*}{$F$} & RAGT + VR & & $15,<0.001$ & $13,<0.001$ & & & \\
\hline & & RAGT-VR & & $4.9,0.003$ & $4.9,0.003$ & & & \\
\hline
\end{tabular}

Legend: $\mathrm{t}$ time, g group, e electrode, $\mathrm{C}$ central, $\mathrm{F}$ frontal, PO parieto-occipital; S1 first stationary phase; S2 second stationary phase; T1 first transition phases; T2 second transition phase

rhythm across the phases of gait cycle. Such a selective modulation allows the patient to complete better the gait training (e.g., to better steer, avoid objects, and keep the line during walking) [113]. These data are in keeping with the role of the premotor areas in planning limb movements [114] and initiating and adapting gait [115-118], and of the parieto-occipital cortex in spatial attention, decision making, sensorimotor integration, and movement planning in visually guided movements under both feedforward and feedback control [119-124]. The specific entrainment of $\gamma$ rhythms when observing a human avatar may depend on a different entrainment of visuomotor networks as compared to the control condition (RAGT-VR). According to the canonical microcircuit model [125], the superficial pyramidal neurons generating $\gamma$-responses act as a dynamic filter on the visual inputs, thus affecting both the configuration of $\gamma$-oscillations (depending on the stimulus properties, including movement, contrast, localization, and size of visual cues) and the $\mu$ and $\beta$ band output dynamics (which are generated by deeper pyramidal neurons) [126-128]. The use of an avatar may have thus specifically increased the frontal-posterior $\gamma$ oscillations. The parieto-occipital $\alpha$-ERD may be instead linked to basic visual processing. In addition, it has been reported that $\mu / \gamma$ ERSP provided by VR feedback is related to the participants' monitoring of their own movements [129-131]. We can therefore hypothesize that these ERSPs in fronto-parietooccipital regions during the observation of performed movements and during visually-guided gait adaptation task potentially express the activation of the MNS.

One could argue that $\mathrm{H} \gamma$ ERSPs may purely reflect motor activation and not specific cognitive processes 


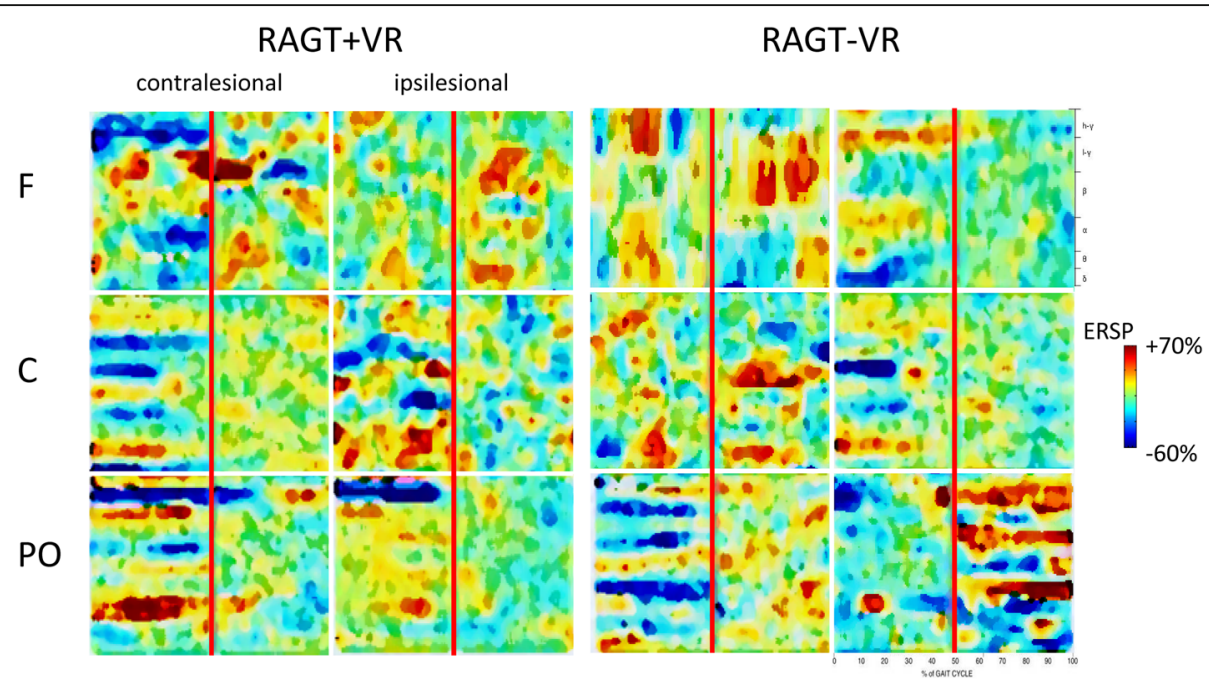

Fig. 4 Average $T_{\text {PRE }}{ }^{-T}$ POST changes in gait event-related spectral perturbation (ERSPS) in RAGT + VR (a) and RAGT-VR (b) groups. Non-significant differences relative to the full gait cycle baseline $(p \leq 0.05)$ are masked in green (see Table 4$)$

related to VR, given that $\gamma$-band ERSPs express also a higher cortico-muscular connection during ambulation [132-134]. Nonetheless, this concern sounds unlikely, since BWS and DGF, which both change muscle activity $[135,136]$, were individually adapted in all patients. Consequently, $\mathrm{L} \gamma$ band (which is instead strongly related to motor activity level) $[132,133,137]$ was similar in the two groups, despite BWS and DGF individual adaptation, whereas Hy ERSPs reflected the presence of VR rather than to motor practice.

A brief 9-ERS (at the beginning of the gait cycle) was present in both groups. It is hypothesizable that 9 -ERS in a non-specific event during gait and it is probably related to the sensorimotor area demand, the basic locomotor control, and the timing of muscular activation patterns $[138,139]$.

ERSPs were lateralized in the affected hemisphere in the RAGT + VR group but not in the group RAGT-VR, despite the lesion localization was similar in both the groups, with the exception of parieto-occipital ERSPs, which were bilateral in both groups, as formerly reported [140]. In fact, visuomotor information processing is distributed symmetrically during walking [140], except for some specialized areas located in the right hemisphere, which are crucial for the closed-loop aspects of the movements depending on the sensory feedback [141]. We may argue that the bi-hemispheric distribution of ERSPs in the RAGT-VR may depend on a dysfunctional reshape of interhemispheric connectivity, which was instead recovered, at least partially, in the RAGT + VR group [142-147].

As limiting factors in our work, we have to acknowledge that patients were provided with objects appearing in different corners of the screen during RAGT + VR. This fact may force eye-movements planning, which is expressed by a decreased $\alpha / \beta$ power within parietooccipital regions [148]. Nonetheless, the extent of difference in brain activation between RAGT + VR and RAGT-VR is sufficiently high to exclude a biasing effect of the activity related to saccades on our data. Moreover, it has been shown that firstperson perspective is superior to third-person perspective VR [149, 150], owing to an enhanced feeling of agency [151]. We could speculate that the increased performances

Table 5 Summarizes the significant PRE-POST differences $(t, p)$ of scalp projections. Not reported data are non-significant

\begin{tabular}{|c|c|c|c|c|c|c|}
\hline \multirow[t]{2}{*}{ band } & \multicolumn{3}{|l|}{$\underline{R A G T}+\mathrm{VR}$} & \multicolumn{3}{|l|}{ RAGT-VR } \\
\hline & $\mathrm{C}$ & $F$ & $\mathrm{PO}$ & $\mathrm{C}$ & $\mathrm{F}$ & $\mathrm{PO}$ \\
\hline$\mu-E R D$ & $5<0.001$ & & $11,<0.001$ & $6,<0.001$ & & $4,<0.001$ \\
\hline$\beta-E R D$ & $10,<0.001$ & & $4,<0.001$ & $6,<0.001$ & $6,<0.001$ & $3,<0.001$ \\
\hline$\mu-E R S$ & $5,<0.001$ & $8,<0.001$ & & $13,<0.001$ & $10,<0.001$ & \\
\hline$\beta-$ ERS & $4,<0.001$ & $13,<0.001$ & & & & \\
\hline$\vartheta-E R S$ & $5,<0.001$ & & $4,<0.001$ & $6,<0.001$ & & $4,<0.001$ \\
\hline LY -ERS & $7,<0.001$ & $4,<0.001$ & & $6,<0.001$ & $22,<0.001$ & \\
\hline $\mathrm{HY}_{\gamma}$-ERD & & $4,<0.001$ & $4,<0.001$ & & & \\
\hline
\end{tabular}

Legend: $\mathrm{t}$ time, g group, e electrode, $\mathrm{C}$ central, $\mathrm{F}$ frontal, $\mathrm{PO}$ parieto-occipital 


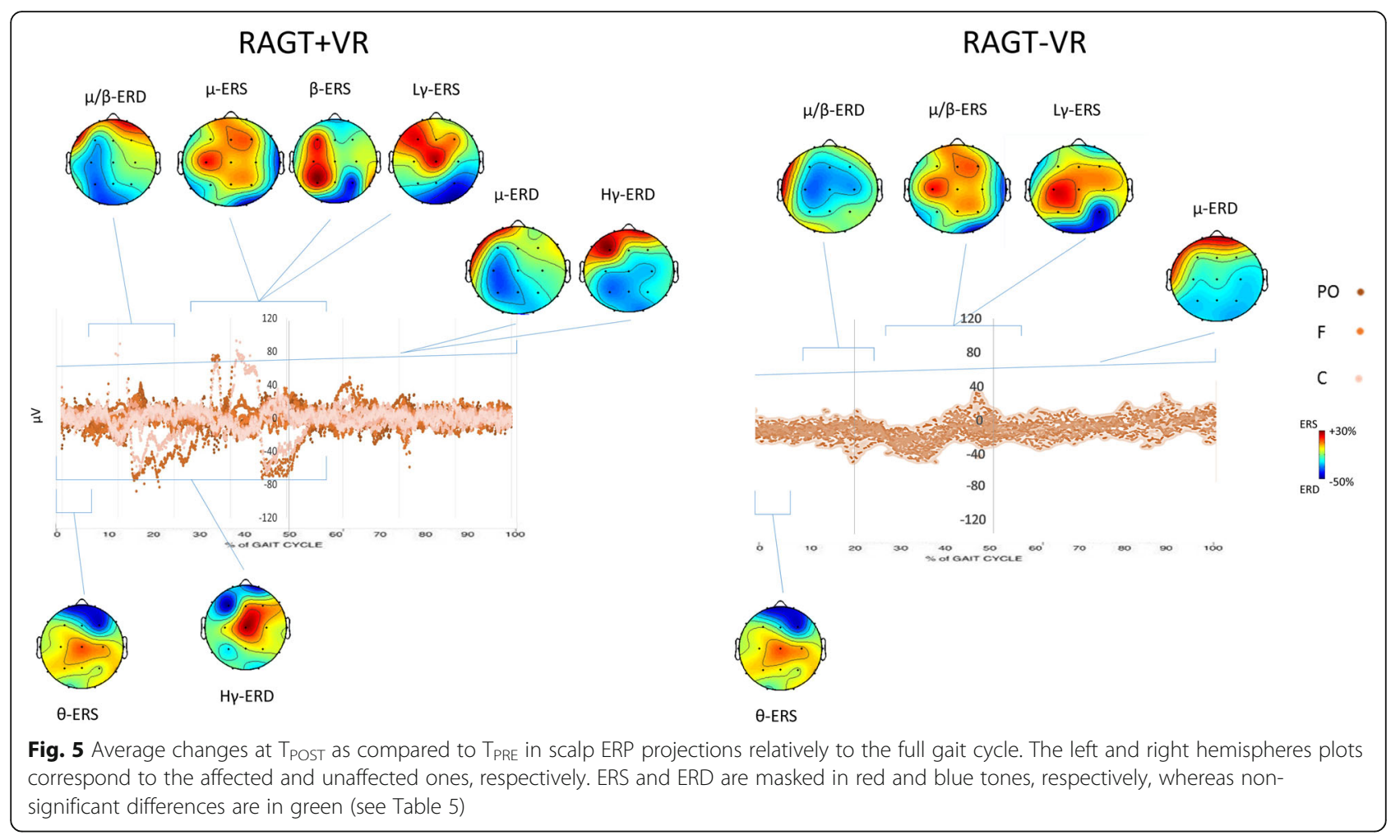

might have induced a greater feeling of agency in the third person perspective. However, studies comparing first- and person perspective are needed to confirm this issue.

Further, the clinical improvement we reported may also depend on factors not directly related to the ERSPs, including a stronger motivation for active participation in the movement provided by the VR [152], as suggested by the few episodes of drowsiness and the high sense of entrainment in the VR setting. A stronger motivation is, however, of notable importance, given that it allows the patient to exercise more regularly, precisely, and intensely [153-156] and, at least indirectly by enhancing the voluntary drive, to improve motor planning, learning and execution $[157,158]$. Thus, our results show anyway the possible benefit of goal directed walking tasks that recruit brain areas involved in motor planning, learning and execution by using VR.

Finally, we employed a relatively low-speed RAGT, which could have affected the timing of muscle activation and amplitude, thus potentially reducing the level of sensorimotor cortex activation. Nonetheless, we preferred to adopt a low-speed RAGT to avoid excessive EEG contamination due to movement artefacts.

In conclusion, our findings suggest that VR feedback during RAGT elicits stronger cortical activations within the fronto-parietooccipital areas potentially belonging to the MNS, and involved in motor intention and planning. These activations were paralleled by an evident improvement in walking ability. We may thus argue the use more demanding and interactive task during RAGT by using VR may be of benefit to the patients with stroke. Moreover, monitoring the EEG in this context allows clinicians to realize better patient-tailored rehabilitative approaches.

\section{Abbreviations}

BWS: Body weight support; EEG: Electroencephalographic; EOG: Electrooculogram; ERD: Event-related desynchronization; ERS: Event-related synchronization; ERSP: Event-related-spectral-perturbation; FFT: Fast Fourier transform; GF: Leg guidance force; HRS: Hamilton Rating Scale for Depression; HS: Heel strike; ICA: Independent component analysis; LORETA: Low Resolution Brain Electromagnetic Tomography; MAS: Modified Ashworth Scale; MNS: Mirror neuron system; MRC: Muscle Research Council; MRI: Magnetic resonance imaging; POMA: Tinetti Performance Oriented Mobility Assessment; PSD: Power spectral density; RAGT: Robot-assisted gait training; VAS: Visual analogue scale; VR: Virtual reality

\section{Acknowledgements}

Not applicable.

\section{Availability of data and materials}

The datasets used and/or analyzed during the current study available from the corresponding author on reasonable request.

\section{Funding}

No funding to be reported.

\section{Authors' contributions}

RSC, AN, MR, AB, PB: 1a, 2b, 3, and 4; AL, RDL, TB, AB, GLR: 1b, 2a, 3, and 4 (legend: 1a Substantial contributions to the conception and design of the work, and interpretation of data; $1 \mathrm{~b}$ acquisition and analysis of data. 2a Drafting the work; $2 b$ revising the work critically for important intellectual content. 3 Final approval of the version to be published. 4 Agreement to be accountable for all aspects of the work in ensuring that questions related to the accuracy or integrity of any part of the work are appropriately 
investigated and resolved). All authors read and approved the final manuscript.

\section{Competing interests}

The authors declare that they have no competing interests.

\section{Consent for publication}

Informed consent was obtained from all individual participants included in the study.

\section{Ethics approval and consent to participate}

All procedures performed in studies involving human participants were in accordance with the ethical standards of the institutional and/or national research committee and with the 1964 Helsinki declaration and its later amendments or comparable ethical standards.

\section{Publisher's Note}

Springer Nature remains neutral with regard to jurisdictional claims in published maps and institutional affiliations.

Received: 23 November 2016 Accepted: 1 June 2017

Published online: 07 June 2017

\section{References}

1. Holden MK. Virtual environments for motor rehabilitation: review. Cyber Psychol Behav. 2005;8:187-211.

2. Riva G, Anguera MT, Wiederhold BK, Mantovani F. From communication to presence: cognition, emotions and culture towards the ultimate communicative experience. Amsterdam: IOS Press; 2006.

3. Nudo R, Milliken G, Jenkins W, Merzenich M. Use-dependent alterations of movement representations in primary motor cortex of adult squirrel monkeys. J Neurosci. 1996;16(2):785-807.

4. Boyd L, Vidoni E, Wessel B. Motor learning after stroke: is skill acquisition a prerequisite for contralesional neuroplastic change. Neurosci Lett. 2010;482:21-5.

5. Nudo R, Milliken G. Reorganization of movement representations in primary motor cortex following focal ischemic infarcts in adult squirrel monkeys. J Neurophysiol. 1996;75(5):2144-9.

6. Plautz E, Milliken $G$, Nudo R. Effects of repetitive motor training on movement representations in adult squirrel monkeys: role of use versus learning. Neurobiol Learn Mem. 2000;74:27-55.

7. Sveistrup H. Motor rehabilitation using virtual reality. J Neuroeng Rehabil. 2004;11:10.

8. Fu MJ, Knutson JS, Chae J. Stroke rehabilitation using virtual environments. Phys Med Rehabil Clin N Am. 2015;26:747-57.

9. Calabrò RS, Russo M, Naro A, De Luca R, Leo A, Tomasello P, Molonia F, Dattola V, Bramanti A, Bramanti P. Robotic gait training in multiple sclerosis rehabilitation: Can virtual reality make the difference? Findings from a randomized controlled trial. J Neurol Sci. 2017;377:25-30.

10. Kwakkel G, Kollen B, Wagenaar R. Therapy impact on functional recovery in stroke rehabilitation: a critical review of the literature. Physiotherapy. 1999; 85(7):377-91.

11. Rossini P, Forno G. Neuronal post-stroke plasticity in the adult. Restorative Neurology and Neurosci. 2004;22(3-5):193-206.

12. Maier I, Schwab M. Sprouting, regeneration and circuit formation in the injured spinal cord: factors and activity. Philos Trans of the R Soc B: Biol Sci. 2006;361(1473):1611-34.

13. Nudo R, Plautz E, Frost S. Role of adaptive plasticity in recovery of function after damage to motor cortex. Muscle Nerve. 2001:24(8):1000-19.

14. Stroemer R, Kent T, Hulsebosch C. Neocortical neural sprouting, synaptogenesis, and behavioral recovery after neocortical infarction in rats. Stroke. 1995;26(11):2135-44.

15. Pavone EF, Tieri G, Rizza G, Tidoni E, Grisoni L, Aglioti SM. Embodying others in immersive virtual reality: electro-cortical signatures of monitoring the errors in the actions of an avatar seen from a first-person perspective. $J$ Neurosci. 2016:36:268-79.

16. Fadiga L, Craighero L. Electrophysiology of action representation. Clin Neurophysiol. 2004:21:157-69.

17. Buccino G, Binkofski F, Fink GR, Fadiga L, Fogassi L, Gallese V, et al. Action observation activates premotor and parietal areas in a somatotopic manner: an fMRI study. Eur J Neurosci. 2001;13:400-4.
18. Ramachandran VS, Hirstein W. The perception of phantom limbs. Brain. 1998:121:1603-30.

19. Pavlova M, Lutzenberger W, Sokolov A, Birbaumer N. Dissociable cortica processing of recognizable and non-recognizable biological movement: analyzing gamma MEG activity. Cereb Cortex. 2004;14:181-8.

20. Modroño C, Navarrete G, Rodríguez-Hernández AF, González-Mora JL. Activation of the human mirror neuron system during the observation of the manipulation of virtual tools in the absence of a visible effector limb. Neurosci Lett. 2013;555:220-4.

21. Buccino G, Solodkin A, Small S. Functions of the mirror neuron system: implications for neurorehabilitation. Cogn Behav Neurol. 2006;19:55-63.

22. Laver K, George S, Thomas S, Deutsch JE, Crotty M. Virtual reality for stroke rehabilitation: an abridged version of a Cochrane review. Eur J Phys Rehabil Med. 2015;51:497-506

23. Krakauer J. Motor learning: its relevance to stroke recovery and neurorehabilitation. Curr Opin Neurol. 2006;19:84-90.

24. Jäncke $L$, Cheetham M, Baumgartner T. Virtual reality and the role of the prefrontal cortex in adults and children. Front Neurosci. 2009;3:52-9.

25. Kravitz DJ, Saleem KS, Baker Cl, Mishkin M. A new neural framework for visuospatial processing. Nat Rev Neurosci. 2011;12:217-30.

26. Miller $\mathrm{R}$. Theory of the normal waking EEG: from single neurones to waveforms in the alpha, beta and gamma frequency ranges. Int J Psychophysiol. 2007;64:18-23.

27. Sharma N, Classen J, Cohen LG. Neural plasticity and its contribution to functional recovery. Handb Clin Neurol. 2013;110:3-12.

28. Oberman LM, Pineda JA, Ramachandran VS. The human mirror neuron system: a link between action observation and social skills. Soc Cogn Affect Neurosci. 2007;2(1):62-6.

29. Zarka D, Cevallos C, Petieau M, Hoellinger T, Dan B, Cheron G. Neural rhythmic symphony of human walking observation: upside-down and uncoordinated condition on cortical theta, alpha, beta and gamma oscillations. Front Syst Neurosci. 2014;8:169.

30. Cheron G, Petit G, Cheron J, et al. Brain oscillations in sport: toward EEG biomarkers of performance. Front Psychol. 2016:7:246.

31. Kazuhiro U, Masataka Y, Hongbo L, Chi Z. Effect of motor intensity on motion imagery with electroencephalogram signal analysis in mirror neuron system. J Neurosci Neuroeng. 2017;4(1):38-43.

32. McGarry LMJ. The role of the mirror neuron system in bottom-up and topdown perception of human action. Canada: Toronto University Press; 2015.

33. Filimon F, Rieth CA, Sereno MI, Cottrell GW. Observed, executed, and imagined action representations can be decoded from ventral and dorsal areas. Cereb Cortex. 2015;25(9):3144-58.

34. Ferreira Dos Santos L, Christ O, Mate K, Schmidt H, Krüger J, Dohle C. Movement visualization in virtual reality rehabilitation of the lower limb: a systematic review. Biomed Eng Online. 2016;15(Suppl 3):144.

35. de Rooij IJ, van de Port IG, Meijer JG. Effect of virtual reality training on balance and gait ability in patients with stroke: systematic review and metaanalysis. Phys Ther. 2016;96(12):1905-18.

36. Chan L, Heinemann AW, Roberts J. Elevating the quality of disability and rehabilitation research: mandatory use of the reporting guidelines. Ann Phys Rehabil Med. 2014:57:558-60.

37. Medical Research Council. Aids to the examination of the peripheral nervous system, memorandum no. 45. London: Pengragon House; 1978.

38. Bohannon RW, Smith MB. Interrater reliability of a modified Ashworth scale of muscle spasticity. Phys Ther. 1987:67(2):206-7.

39. Foreman B, Claassen J. Quantitative EEG for the detection of brain ischemia. Crit Care. 2012;16(2):216.

40. You RX, McNeil JJ, O'Malley HM, Davis SM, Thrift AG, Donnan GA. Risk factors for stroke due to cerebral infarction in young adults. Stroke. 1997;28(10):1913-8.

41. Song GB, Park EC. Effect of virtual reality games on stroke patients' balance, gait, depression, and interpersonal relationships. J Phys Ther Sci. 2015;27(7): 2057-60.

42. de Rooij IJ, van de Port IG, Meijer JG. Effect of virtual reality training on balance and gait ability in patients with stroke: systematic review and metaanalysis. J Neuroeng Rehabil. 2015;12:46

43. Darekar A, McFadyen BJ, Lamontagne A, Fung J. Efficacy of virtual realitybased intervention on balance and mobility disorders post-stroke: a scoping review. Biomed Res Int. 2016:2016:7309272.

44. Ling C, Wai LAL, Yu RM, Ming HD, Qiang L, Hai L, et al. Effect of virtual reality on postural and balance control in patients with stroke: a systematic literature review. Biomed Res Int. 2016;2016:7309272. 
45. Riener R, Lunenburger L, Jezernik S, Anderschitz M, Colombo G, Dietz V. Patient cooperative strategies for robot-aided treadmill training: first experimental results. IEEE Trans Neur Syst Reh. 2005;13(3):380-94.

46. Riener R, Lunenburger L, Colombo G. Human-centered robotics applied to gait training and assessment. J Rehabil Res Dev. 2006:43(5):679-94.

47. Wirz M, Zemon DH, Rupp R, Scheel A, Colombo G, Dietz V, et al. Effectiveness of automated locomotor training in patients with chronic incomplete spinal cord injury: a multicenter trial. Arch Phys Med Rehabil. 2005;86(4):672-80.

48. Hornby TG, Zemon DH, Campbell D. Robotic-assisted, body-weight-supported treadmill training in individuals following motor incomplete spinal cord injury. Phys Ther. 2005;85(1):52-66.

49. Light GA, Williams LE, Minow F, Sprock J, Rissling A, Sharp R, Swerdlow NR, Braff DL. Electroencephalography (EEG) and Event-Related Potentials (ERP's) with Human Participants. Curr Protoc Neurosci. 2010;6:2524.

50. Lisi G, Morimoto J. EEG single-trial detection of gait speed changes during treadmill walk. PLoS One. 2015;10(5):e0125479.

51. Kilicarslan A, Grossman RG. Contreras-Vidal JL. A robust adaptive denoising framework for real-time artifact removal in scalp EEG measurements. J Neural Eng. 2016;13:026013.

52. Fruhstorfer $H$, Langanke $P$, Meinzer $K$, Peter JH, Pfaff U. Neurophysiological vigilance indicators and operational analysis of a train vigilance monitoring device: a laboratory and field study. In: Mackie RR, editor. Vigilance. New York: Plenum Press; 1977. p. 147-62.

53. Makeig S, Debener S, Onton J, Delorme A. Mining event-related brain dynamics. Trends Cogn Sci. 2004;8(5):204-10.

54. Wagner J, Solis-Escalante T, Grieshofer P, Neuper C, Müller-Putz G, Scherer R. Level of participation in robotic-assisted treadmill walking modulates midline sensorimotor EEG rhythms in able-bodied subjects. Neurolmage. 2012;63:1203-11

55. Onton J, Westerfield M, Townsend J, Makeig S. Imaging human EEG dynamics using independent component analysis. Neurosci Biobehav Rev. 2006;30:808-22.

56. Gwin JT, Gramann K, Makeig S, Ferris DP. Electrocortical activity is coupled to gait cycle phase during treadmill walking. Neurolmage. 2010;54:1289-96.

57. Delorme A, Makeig S. EEGLAB: an open source toolbox for analysis of single-trial EEG dynamics including independent component analysis. J Neurosci Methods. 2004;134:9-21

58. Makeig S. Auditory event-related dynamics of the EEG spectrum and effects of exposure to tones. Electroencephalogr Clin Neurophysiol. 1993;86:283-93.

59. Perry J, Burnfield JM. Gait analysis, normal and pathological function. J Sports Sci Med. 2010;9(2):353.

60. Delorme A, Sejnowski T, Makeig S. Enhanced detection of artifacts in EEG data using higher-order statistics and independent component analysis. Neurolmage. 2007;34(4):1443-9.

61. Nathan K, Contreras-Vidal JL. Negligible motion artifacts in scalp electroencephalography (EEG) during treadmill walking. Front Hum Neurosci. 2016;9:708

62. Castermans T, Duvinage M, Cheron G, Dutoit T. Towards effective noninvasive brain-computer interfaces dedicated to gait rehabilitation systems. Brain Sci. 2014;4:1-48.

63. Pfurtscheller $G$, Neuper C. Event-related synchronization of mu rhythm in the EEG over the cortical hand area in man. Neurosci Lett. 1994;174:93-6.

64. Andrew C, Pfurtscheller G. On the existence of different alpha band rhythms in the hand area of man. Neurosci Lett. 1997;222(2):103-6.

65. Frenkel-Toledo S, Bentin S, Perry A, Liebermann DG, Soroker N. Dynamics of the EEG power in the frequency and spatial domains during observation and execution of manual movements. Brain Res. 2013;1509:43-57.

66. Frenkel-Toledo S, Bentin S, Perry A, Liebermann DG, Soroker N. Mirrorneuron system recruitment by action observation: effects of focal brain damage on mu suppression. Neurolmage. 2014;87:127-37.

67. Taborri J, Palermo E, Rossi S, Cappa P. Gait Partitioning Methods: A Systematic Review. Sensors (Basel, Switzerland). 2016;16:66.

68. Rajmohan V, Mohandas E. Mirror neuron system. Indian J Psychiatry. 2007; 49:66-69.

69. Kilner JM, Lemon RN. What we know currently about mirror neurons. Curr Biol. 2013;23(23):R1057-62

70. Schippers MB, Keysers C. Mapping the flow of information within the putative mirror neuron system during gesture observation. Neurolmage. 2011;57(1):37-44.
71. Braadbaart L, Williams JH, Waiter GD. Do mirror neuron areas mediate mu rhythm suppression during imitation and action observation? Int J Psychophysiol. 2013;89(1):99-105.

72. Demiralp T, Bayraktaroglu Z, Lenz D, Junge S, Busch NA, Maess B, et al. Gamma amplitudes are coupled to theta phase in human EEG during visual perception. Int J Psychophysiol. 2007;64(1):24-30.

73. de Lange FP, Jensen $\mathrm{O}$, Bauer M, Toni I. Interactions between posterior gamma and frontal alpha/beta oscillations during imagined actions. Front Hum Neurosci. 2008;2:7.

74. Pfurtscheller G, Neuper C. Event-related synchronization of mu rhythm in the EEG over the cortical hand area in man. Neurosci Lett. 2011;174:93-6.

75. Pascual-Marqui RD. Review of methods for solving the EEG inverse problem. Int J Bioelectromagn. 1999;1:75-86.

76. Pascual-Marqui RD, Michel CM, Lehmann D. Low resolution electromagnetic tomography: a new method for localizing electrical activity in the brain. Int J Psychophysiol. 1994;18:49-65.

77. Fuchs M, Drenckhahn R, Wischmann HA, Wagner M. An improved boundary element method for realistic volume-conductor modeling. IEEE Trans Biomed Eng. 1998:45:980-97.

78. Fuchs M, Kastner J, Wagner M, et al. A standardized boundary element method volume conductor model. Clin Neurophysiol. 2002;113:702-12.

79. Basile LF, Yacubian J, Castro CC, Grattaz WF. Widespread electrical cortical dysfunction in schizophrenia. Schizophr Res. 2004;69:255-66.

80. Yao J, Dewald JP. Evaluation of different cortical source localization methods using simulated and experimental EEG data. Neurolmage. 2005;25:369-82.

81. Chen HM, Hsieh CL. Sing Kai lo, Liaw LJ, Chen SM, Lin JH. The test-retest reliability of 2 mobility performance tests in patients with chronic stroke. Neurorehabil Neural Repair. 2007;21(4):347-52

82. Canbek J, Fulk G, Nof L, Echternach J. Test-retest reliability and construct validity of the tinetti performance-oriented mobility assessment in people with stroke. J Neurol Phys Ther. 2013;37(1):14-9.

83. Monge-Pereira E, Molina-Rueda F, Rivas-Montero FM, Ibáñez J, Serrano II, Alguacil-Diego IM, et al. Electroencephalography as a post-stroke assessment method: an updated review. Neurologia. 2017;32(1):40-9.

84. Knaepen K, Mierau A, Swinnen E, Fernandez Tellez H, Michielsen M,

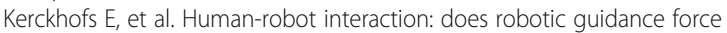
affect gait-related brain dynamics during robot-assisted treadmill walking? PLoS One. 2015;10(10):e0140626.

85. Dobkin BH, Duncan PW. Should body weight-supported treadmill training and robotic-assistive steppers for locomotor training trot back to the starting gate? Neurorehabil Neural Repair. 2012;26:308-17.

86. Wutzke CJ, Mercer VS, Lewek MD. Influence of lower extremity sensory function on locomotor adaptation following stroke: a review. Top Stroke Rehabil. 2013;20(3):233-40.

87. Park W, Kwon GH, Kim YH, Lee JH, Kim L. EEG response varies with lesion location in patients with chronic stroke. J Neuroeng Rehabil. 2016;13:21.

88. Wu J, Quinlan EB, Dodakian L, et al. Connectivity measures are robust biomarkers of cortical function and plasticity after stroke. Brain. 2015;138(8): 2359-69. doi:10.1093/brain/awv156.

89. Perry J. Gait analysis: normal and pathological function. Thorofare: Slack Incorporated; 1992.

90. Benjamini $Y$, Yekutieli $D$. The control of the false discovery rate in multiple testing under dependency. Ann Stat. 2001;29:1165-88.

91. Pfurtscheller G, Lopes da Silva F. Event-related EEG/MEG synchronization and desynchronization: basic principles. Clin Neurophysiol. 1999;110:1842-57.

92. Crone NE, Miglioretti DL, Gordon B, Sieracki JM, Wilson MT, Uematsu S, et al. Functional mapping of human sensorimotor cortex with electrocorticographic spectral analysis. I. Alpha and beta event-related desynchronization. Brain. 1998;121:2271-99.

93. Gilbertson T, Lalo E, Doyle L, Di Lazzaro V, Cioni B, Brown P. Existing motor state is favored at the expense of new movement during $13-35 \mathrm{~Hz}$ oscillatory synchrony in the human corticospinal system. J Neurosci. 2005:25:7771-9.

94. Jenkinson N, Brown P. New insights into the relationship between dopamine, beta oscillations and motor function. Trends Neurosci. 2011;34:611-8.

95. Joundi RA, Jenkinson N, Brittain JS, Aziz TZ, Brown P. Driving oscillatory activity in the human cortex enhances motor performance. Curr Biol. 2012;22:403-7.

96. Klimesch W, Sauseng P, HansImayr S. EEG alpha oscillations: the inhibitiontiming hypothesis. J Neurosci. 2007:53:63-88. 
97. Miller K, Leuthardt EC, Schalk G, Rao RP, Anderson NR, Moran DW, et al. Spectral changes in cortical surface potentials during motor movement. J Neurosci. 2007;27:2424-32.

98. Neuper C, Pfurtscheller G. Event-related dynamics of cortical rhythms: frequency-specific features and functional correlates. Int J Psychophysiol. 2001;43:41-58

99. Neuper C, Wörtz M, Pfurtscheller G. ERD/ERS patterns reflecting sensorimotor activation and deactivation. J Neurosci. 2007;27:2424-32.

100. Knill DC, Maloney LT, Trommershäuser J. Sensorimotor Processing and GoalDirected Movement. J Vis. 2007;7:1-2.

101. Pfurtscheller G, Graimann B, Huggins JE, Levine SP, Schuh LA. Spatiotemporal patterns of beta desynchronization and gamma synchronization in corticographic data during self-paced movement. Clin Neurophysiol. 2003;114:1226-36.

102. Pfurtscheller G, Stancak J, Neuper C. Post-movement beta synchronization. A correlate of an idling area. Electroencephalogr. Clin. Neurophysiology. 1996;98:281-93.

103. Alegre M, Labarga A, Gurtubay IG, Iriarte J, Malanda A, Artieda J. Movementrelated changes in cortical oscillatory activity in ballistic, sustained and negative movements. Exp Brain Res. 2003;148:17-25.

104. Brown P. Cortical drives to human muscle: the piper and related rhythms. Prog Neurobiol. 2000;60:97-108.

105. Cavanna AE, Trimble MR. The precuneus: a review of its functional anatomy and behavioural correlates. Brain. 2006;129:564-83.

106. Mima T, Steger J, Schulman AE, Gerloff C, Hallett M. Electroencephalographic measurement of motor cortex control of muscle activity in humans. Clin Neurophysiol. 2000;111:326-37.

107. Müller-Putz P, Neuper C, Rupp R, Keinrath C, Gerner H, Pfurtscheller G. Event-related beta electroencephalographic changes during wrist movements induced by functional electrical stimulation of forearm muscles in man. Neurosci Lett. 2003;340:143-7.

108. Müller-Putz P, Zimmermann D, Graimann B, Nestinger K, Korisek G, Pfurtscheller G. Event-related beta EEG-changes during passive and attempted foot movements in paraplegic patients. Brain Res. 2007;1137:84-91.

109. Pfurtscheller G, Neuper C. Simultaneous EEG $10 \mathrm{~Hz}$ desynchronization and $40 \mathrm{~Hz}$ synchronization during finger movements. Neuroreport. 1992;3:1057-60.

110. Pfurtscheller G, Neuper C, Kalcher J. 40-hz oscillations during motor behavior in man. Neurosci Lett. 1993;164:179-82.

111. Raethjen J, Govindan RB, Binder S, Zeuner KE, Deuschl G, Stolze H. Cortical representation of rhythmic foot movements. Brain Res. 2008;1236:79-84.

112. Sahyoun C, Floyer-Lea A, Johansen-Berg H, Matthews PM. Towards an understanding of gait control: brain activation during the anticipation, preparation and execution of foot movements. Neurolmage. 2004;21(2):568-75.

113. Gwin JT, Gramann K, Makeig S, Ferris DP. Electrocortical activity is coupled to gait cycle phase during treadmill walking. Neurolmage. 2011;54(2):1289-96.

114. Haggard P. Human volition: towards a neuroscience of will. Nat Rev Neurosci. 2008;9:934-46

115. Haefeli J, Vögeli S, Michel J, Dietz V. Preparation and performance of obstacle steps: interaction between brain and spinal neuronal activity. Eur J Neurosci. 2011;33:338-48.

116. Koenraadt KL, Roelofsen EG, Duysens J, Keijsers NL. Cortical control of normal gait and precision stepping: an fNIRS study. Neurolmage. 2013;85:415-22

117. Suzuki M, Miyai I, Ono T, Kubota K. Activities in the frontal cortex and gait performance are modulated by preparation. An fNIRS study. Neurolmage. 2008;39:600-7.

118. Suzuki M, Miyai I, Ono T, Oda I, Konishi I, Kochiyama T, et al. Prefrontal and premotor cortices are involved in adapting walking and running speed on the treadmill: an optical imaging study. Neurolmage. 2004;23:1020-6.

119. Capotosto P, Babiloni C, Romani GL, Corbetta M. Frontoparietal cortex controls spatial attention through modulation of anticipatory alpha rhythms. J Neurosci. 2009;29:5863-72.

120. Capotosto P, Babiloni C, Romani GL, Corbetta M. Differential contribution of right and left parietal cortex to the control of spatial attention: a simultaneous EEG-rTMS study. Cereb Cortex. 2012;22:446-54.

121. Donner TH, Siegel M. A framework for local cortical oscillation patterns. Trends Cogn Sci. 2011;15:191-9.

122. Hipp JF, Engel AK, Siegel M. Oscillatory synchronization in large-scale cortical networks predicts perception. Neuron. 2011;69:387-96.
123. Perfetti B, Moisello C, Landsness EC, Kvint S, Pruski A, Onofrj M, et al Temporal evolution of oscillatory activity predicts performance in a choicereaction time reaching task. J Neurophysiol. 2011;105:18-27.

124. Tombini M, Zappasodi F, Zollo L, Pellegrino G, Cavallo G, Tecchio F, et al. Brain activity preceding a 2D manual catching task. Neurolmage. 2009:47:1735-46.

125. Bastos AM, Usrey WM, Adams RA, Mangun GR, Fries P, Friston KJ. Canonical microcircuits for predictive coding. Neuron. 2012;76:695-711.

126. Ray S, Maunsell JHR. Differences in gamma frequencies across visual cortex restrict their possible use in computation. Neuron. 2010;67:885-96.

127. Brunel N, Wang XJ. What determines the frequency of fast network oscillations with irregular neural discharges? I. Synaptic dynamics and excitation-inhibition balance. J Neurophysiol. 2003;90:415-30.

128. Roberts MJ, Lowet E, Brunet NM, Ter Wal M, Tiesinga P, Fries P, et al. Robust gamma coherence between macaque $\mathrm{V} 1$ and $\mathrm{V} 2$ by dynamic frequency matching. Neuron. 2013;78:523-36.

129. Desmurget M, Reilly KT, Richard N, Szathmari A, Mottolese C, Sirigu A. Movement intention after parietal cortex stimulation in humans. Science. 2009:324:811-3.

130. Drew T, Andujar JE, Lajoie K, Yakovenko S. Cortical mechanisms involved in visuomotor coordination during precision walking. Brain Res Rev. 2008;57: 199-211.

131. Fogassi L, Ferrari PF, Gesierich B, Rozzi S, Chersi F, Rizzolatti G. Parietal lobe: from action organization to intention understanding. Science. 2005;308:662-7.

132. Wagner J, Solis-Escalante T, Scherer R, Neuper C, Muller-Putz G. It's how you get there: walking down a virtual alley activates premotor and parietal areas. Front Hum Neurosci. 2014;8:93.

133. Seeber M, Scherer R, Wagner J, Solis-Escalante T, Muller-Putz GR. EEG beta suppression and low gamma modulation are different elements of human upright walking. Front Hum Neurosci. 2014:8:485.

134. Fries $P$. Neuronal gamma-band synchronization as a fundamental process in cortical computation. Annu Rev Neurosci. 2009;32:209-24.

135. Presacco A, Goodman R, Forrester L, Contreras-Vidal JL. Neural decoding of treadmill walking from noninvasive electroencephalographic signals. J Neurophysiol. 2011;106:1875-87.

136. Moreno JC, Barroso F, Farina D, Gizzi L, Santos C, Molinari M, et al. Effects of robotic guidance on the coordination of locomotion. J Neuroeng Rehabil. 2013;10:79.

137. Aru J, Axmacher N, Do Lam ATA, Fell J, Elger CE, Singer W, et al. Local category-specific gamma band responses in the visual cortex do not reflect conscious perception. J Neurosci. 2012;32:14909-14.

138. Petersen TH, Willerslev-Olsen M, Conway BA, Nielsen JB. The motor cortex drives the muscles during walking in human subjects. J Physiol. 2012;590: 2443-52.

139. Vidal JR, Perrone-Bertolotti M, Levy J, De Palma L, Minotti L, Kahane P, et al. Neural repetition suppression in ventral occipito-temporal cortex occurs during conscious and unconscious. Neurolmage. 2012:95:129-35.

140. Nobre AC, Sebestyen GN, Gitelman DR, Mesulam MM, Frackowiak RS, Frith CD. Functional localization of the system for visuospatial attention using positron emission tomography. Brain. 1997;120:515-33.

141. Serrien DJ, Ivry RB, Swinnen SP. Dynamics of hemispheric specialization and integration in the context of motor control. Nat Rev Neurosci. 2006;7:160-6.

142. Cao Y, D'Olhaberriague L, Vikingstad EM, et al. Pilot study of functional MRI to assess cerebral activation of motor function after poststroke hemiparesis. Stroke. 1998:29:112-22.

143. Chen R, Gerloff C, Hallett M, Cohen LG. Involvement of the ipsilateral motor cortex in finger movements of different complexities. Ann Neurol. 1997:41:247-54

144. Mima T, Toma K, Koshy B, Hallett M. Coherence between cortical and muscular activities after subcortical stroke. Stroke. 2001;32:2597-601.

145. Gerloff C, Bushara K, Sailer A, et al. Multimodal imaging of brain reorganization in motor areas of the contralesional hemisphere of well recovered patients after capsular stroke. Brain. 2006;129:791-808.

146. Roland PE, Skinhoj E, Lassen NA, Larsen B. Different cortical areas in man in organization of voluntary movements in extrapersonal space. J Neurophysiol. 1980;43:137-50.

147. Kim SG, Ashe J, Hendrich K, et al. Functional magnetic resonance imaging of motor cortex: hemispheric asymmetry and handedness. Science. 1993;261:615-7.

148. Snyder LH, Batista AP, Andersen RA. Coding of intention in the posterior parietal cortex. Nature. 1997;386:167-70. 
149. Petkova VI, Khoshnevis M, Ehrsson HH. The perspective matters! Multisensory integration in ego-centric reference frames determines full-body ownership. Front Psychol. 2011;2:35.

150. Slater M, Spanlang B, Sanchez-Vives MV, Blanke O. First per- son experience of body transfer in virtual reality. PLoS One. 2010;5:e10564.

151. Tsakiris M, Longo MR, Haggard P. Having a body versus moving your body: neural signatures of agency and body-ownership. Neuropsychologia. 2010; 48:2740-9.

152. Meadows CC, Gable PA, Lohse KR, Miller MW. Motivation and motor cortical activity can independently affect motor performance. Neuroscience. 2016;339:174-9.

153. Brütsch K, Schuler T, Koenig A, Zimmerli L, Merillat-Koeneke S, Lünenburger $L$, et al. Influence of virtual reality soccer game on walking performance in robotic assisted gait training for children. J Neuroeng Rehabil. 2010;7:15.

154. Brütsch K, Koenig A, Zimmerli L, Merillat-Koeneke S, Riener R, Jäncke $L$, et al. Virtual reality for enhancement of robot-assisted gait training in children with neurological gait disorders. J Rehabil Med. 2011:43:493-9.

155. Schuler T, Brütsch K, Müller R, van Hedel H, Meyer-Heim A. Virtual realities as motivational tools for robotic assisted gait training in children: a surface electromyography study. NeuroRehabilitation. 2011;28:401-11.

156. Zimmerli L, Jacky M, Lünenburger L, Riener R, Bolliger M. Increasing patient engagement during virtual reality based motor rehabilitation. Arch Phys Med. 2013;94:1737-46

157. Kaelin-Lang A, Sawaki L, Cohen LG. Role of voluntary drive in encoding an elementary motor memory. J Neurophysiol. 2005;93:1099-103.

158. Lotze M, Braun C, Birbaumer N, Anders S, Cohen LG. Motor learning elicited by voluntary drive. Brain. 2003;126:866-72.

\section{Submit your next manuscript to BioMed Central and we will help you at every step:}

- We accept pre-submission inquiries

- Our selector tool helps you to find the most relevant journal

- We provide round the clock customer support

- Convenient online submission

- Thorough peer review

- Inclusion in PubMed and all major indexing services

- Maximum visibility for your research

Submit your manuscript at www.biomedcentral.com/submit 